\title{
The Main Mechanical Structure of Large Vacuum Vessel Stress analysis and optimization
}

\author{
Liang $\mathrm{Yi}^{\mathrm{a}}$, Yang Luo ${ }^{\mathrm{b}, *}$, Jian Chen ${ }^{\mathrm{c}}, \mathrm{Yu} \mathrm{Chu}^{\mathrm{d}}$, Shaoxiang $\mathrm{Wu}^{\mathrm{e}}$
}

School of Manufacturing science and engineering, Sichuan University, Chengdu 610065, Sichuan, China

a865336416@qq.com, b376839194@qq.com, ‘676012675@qq.com, d405720104@qq.com, e455227055@qq.com

Keywords: vacuum vessel; finite element; structural design; ANSYS Workbench.

Abstract. The vacuum vessel has been used extensively in aerospace and other equipments. This thesis shows the model simplification for the well-designed vacuum vessel room through solidworks, and also finite element analysis of simplified model is given by applying ANSYS Workbench. After the press and transformation situation is achieved, optimization of the structure is conducted. The results show that, after the optimization of the Stiffening ring, the stress and deformation of the vessel can be reduced and the partial structure of vacuum vessel is also optimized effectively.

\section{Introduction}

With the rapid development of aerospace enterprise, the vacuum industry flourishes too. The large intelligent environment simulation equipment is a kind of complex equipment, providing vacuum, temperature and various kinds of space environment simulations for satellites, spacecrafts and space stations and other aerospace equipments, which is of great significance for the test of our country's aerospace equipments [1].

Moreover, the vacuum vessel is an important part in large intelligent space environment simulation equipment. When it works in extreme ultralow temperature and vacuum condition, the stress strain distribution characteristics directly affects the working process of the simulation, which has important influence on the performance of environmental simulation equipment. [2].

This thesis simplifies the existing vacuum vessel model with solidworks and uses the Ansys workbench software to perform limit element analysis. After the finite element analysis of the deformation and stress, the weak parts of the vacuum vessel are found. When the optimization design of the weak parts in vacuum v•essel is finished, the vacuum vessel that satisfies the intensity and reformation requirement is gotten and the check time and cost is also decreased greatly.

\section{The Establishment of Limit Element Model for Vacuum Vessel}

Because the model is a large vacuum vessel with complicated structure and the finite element calculation is complex, the solidworks is used here to draw a sketch of a large-scale vacuum vessel and conduct the finite element analysis in ansys workbench [3], as is shown in figure 1.
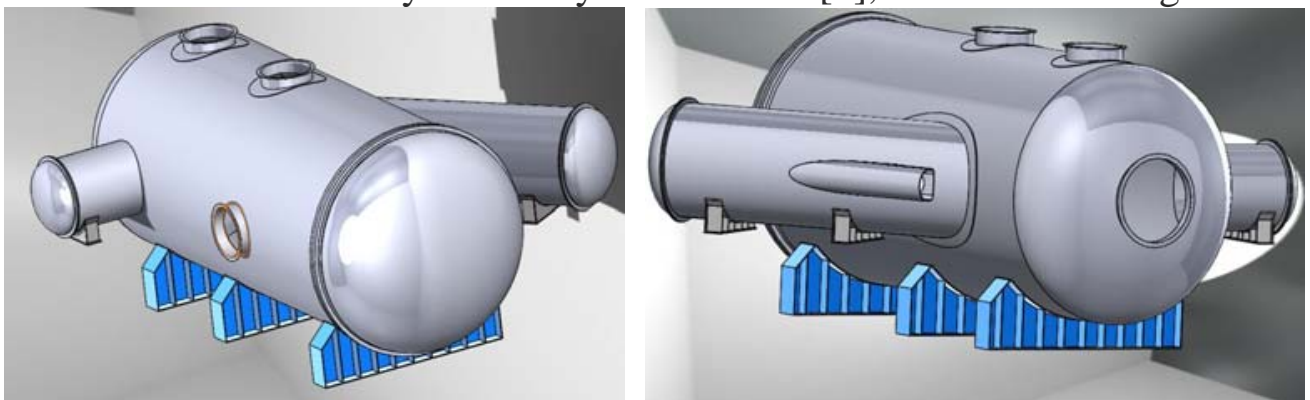

Figure 1.the three-dimensional sketch of vacuum vessel 
Putting the three-dimensional sketch drawn by solidworks to the ANSYS Workbench 15.0 through the plug-in module in solidworks, after which the analysis can be performed.

\section{The Limit Element Analysis of Vacuum Vessel}

\subsection{The Manipulation Before Analysis}

The situation under stress: the main vessel is vacuum inside and one standard atmospheric pressure is applied from outside. Two cold pump flanges with the diameter of $1250 \mathrm{~mm}$ on the top of the main vessel are added downward weight of 16.8t (including the 4.5t weight of atmospheric pressure, cryogenic pumps, control valves and its pipeline); An atmospheric pressure of $1.23 \times 105 \mathrm{~N}$ is applied on the side flange with diameter of $1250 \mathrm{~mm}$ and the atmospheric pressure of $2.54 \mathrm{x} 105 \mathrm{~N}$ is applied on the flange face of $1800 \mathrm{~mm}$ diameter. The sun simulator is applied with $47600 \mathrm{~N}$ of atmospheric pressure. Considering the gravity of vessel and supporting [5], the main stress analysis figure is shown in figure 2.

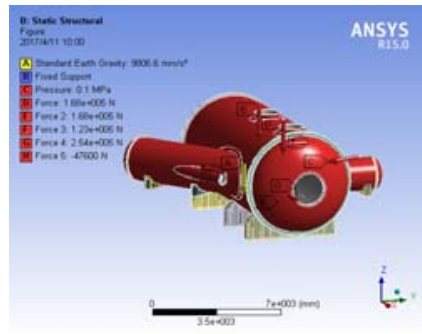

Figure 2. The stress analysis figure

Meshing uses the whole grid control, relevance chooses 15, and Element Size chooses $79 \mathrm{~mm}$ (the smallest unit Size), which generated 1496518 nodes totally and 730258 units. The meshing result figure of vacuum vessel is shown in figure 3.

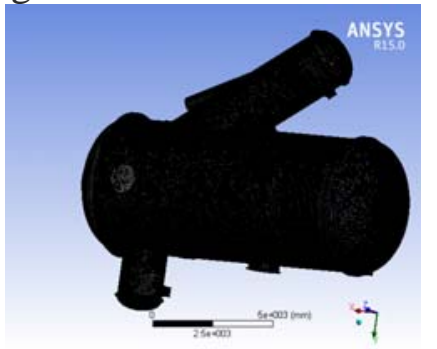

Figure 3. Meshing

\subsection{The Analysis of the Result}

After the load and constraint conditions are applied on the vacuum vessel, the maximum stress and maximum displacement point can be calculated in ANSYS Workbench, namely the stress and displacement situation in normal working condition of the vacuum vessel. The stress and displacement situation are shown in figure 4 and figure 5.

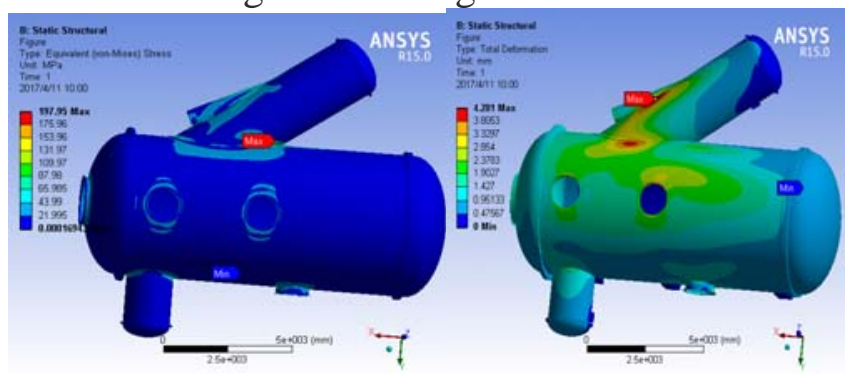

Figure4. The whole stress distribution of main vessel figure 5. The whole deformation and displacement of the main vessel

From figure 4 and 5, under normal working condition, and under the affection of atmospheric pressure and gravity, the vacuum vessel body has the maximal displacement of $4.28 \mathrm{~mm}$ appearing at the top of sun simulator. The maximum combined stress is $197.95 \mathrm{Mpa}$, appearing on the saddle 
under the sun simulator. The stress and displacement of the vessel's critical positions are shown in Tab.1:

Tab.1 The displacement and stress situation of structures in main vessel

\begin{tabular}{|c|c|c|c|c|c|c|}
\hline \multirow{2}{*}{$\begin{array}{l}\text { Analysis } \\
\text { items }\end{array}$} & \multirow{2}{*}{ Key positions } & \multicolumn{2}{|c|}{ Design basis } & \multicolumn{2}{|c|}{ Analysis results } & \multirow{2}{*}{$\begin{array}{l}\text { Yield } \\
\text { strengt } \\
\mathrm{h} \text { of } \\
\text { materia } \\
\text { ls } / \mathrm{MPa}\end{array}$} \\
\hline & & Known quantity & $\begin{array}{l}\text { Loading quantity(1.3times } \\
\text { safety factor) }\end{array}$ & $\begin{array}{l}\text { Maximum } \\
\text { stress } / \mathrm{MPa}\end{array}$ & $\begin{array}{c}\text { Maximum } \\
\text { displacement } / \mathrm{mm}\end{array}$ & \\
\hline \multirow{5}{*}{$\begin{array}{l}\text { Structural } \\
\text { analysis } \\
\text { of main } \\
\text { vessel }\end{array}$} & DN1250 gate valve interface & the weight of DN 1250 & & 75.36 & \multirow{5}{*}{4.28} & 205 \\
\hline & DN1800 gate valve interface & flange interface & Loading one standara & 83.62 & & 205 \\
\hline & The sun simulator & cryogenic pump and its & atmospheric pressure of the & 112.58 & & 205 \\
\hline & Spectral calibration tank & accessory parts on the & flange opening is applied & 85.26 & & 205 \\
\hline & $\begin{array}{l}\text { The main vessel } \\
\text { saddle }\end{array}$ & $\begin{array}{c}\text { one standard } \\
\text { atmospheric pressure is } \\
\text { loaded }\end{array}$ & $\begin{array}{l}\text { according to the area), and the } \\
\text { DN1250 flange interface above } \\
\text { the vessel has the load of 5.85t. }\end{array}$ & 89.23 & & 235 \\
\hline
\end{tabular}

The Tab.1 shows that, because the yield strength of 304 stainless steel is $205 \mathrm{MPa}$, barely meeting the strength requirements, according to GB150 vacuum container design manual, the assurance factor of carbon steel's yield strength generally is 1.6 and stainless steel's strength assurance factor generally is 1.5 , the key positions have reached the design requirements, but considering the relatively high stress of the saddle under the sun simulator, improvement measures should be taken [6].

\section{Stress Analysis of Vacuum Vessel after Reinforcement with Steel}

In practical production, If the reinforcement method is used, it can not only reduce the stress of the container but also lower the cost to some extent. According to the analysis above, the deformation of the sun simulator light cone is greater, and the main vessel tank structure is most important. Therefore, eight annular reinforcing rings and the material Q235 steel- B with the height of $240 \mathrm{~mm}$ and thickness of $180 \mathrm{~mm}$ are equipped on the shell, and the light cone of sun simulator is reinforced with steel [7], as is shown in figure 6:

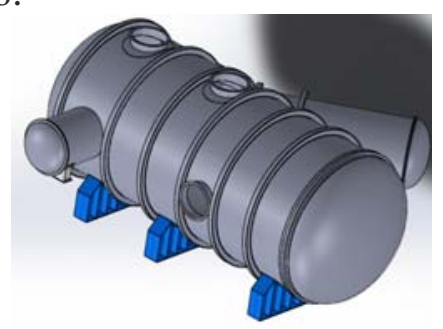

Figure 6. The model sketch after reinforcement with steel

Set again the analysis method of limit element like mentioned above, the force is not changed and the stress and displacement are given. The maximum stress appears at the top of main vessel, which is near to the intersection of the auxiliary vessel of the sun simulator and the main vessel, the maximum stress is $151 \mathrm{MPa}$, the maximal displacement is located in the DN1250 gate valve outlet on main container top and the maximal displacement is $2.3 \mathrm{~mm}$, as is shown in figure 7 and 8 :

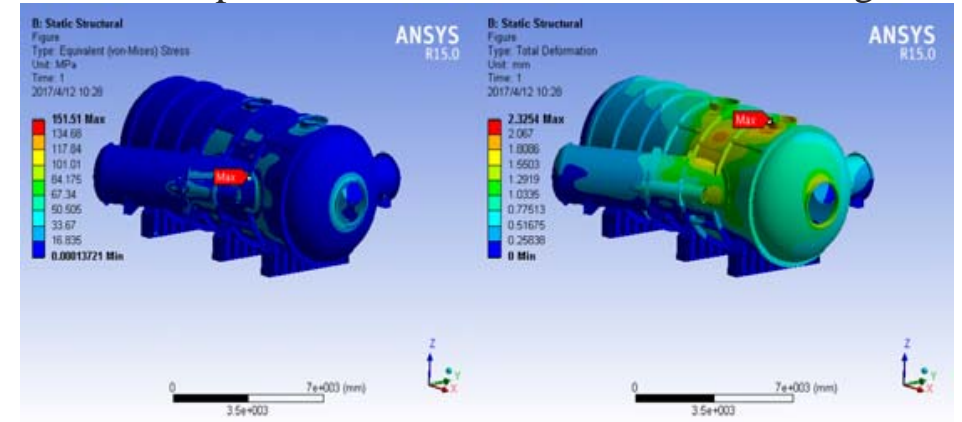

Figure 7. The whole stress distribution of main vessel after reinforcement with steel

Figure 8. The whole deformation and displacement of main vessel after reinforcement with steel

By analyzing the results after the reinforcement with steel, the contrast analysis of the stress and displacement before and after the reinforcement with steel is shown in Tab. 2: 
Tab. 2 the contrast result after analyzing

\begin{tabular}{|c|c|c|c|c|c|c|c|c|}
\hline \multirow[b]{2}{*}{$\begin{array}{l}\text { Analysis } \\
\text { items }\end{array}$} & \multirow[b]{2}{*}{$\begin{array}{c}\text { Key } \\
\text { positions }\end{array}$} & \multicolumn{2}{|c|}{ Design basis } & \multicolumn{4}{|c|}{ Analysis results } & \multirow{2}{*}{$\begin{array}{l}\text { The yield } \\
\text { strength of } \\
\text { materials/MPa }\end{array}$} \\
\hline & & $\begin{array}{l}\text { Known } \\
\text { quantity }\end{array}$ & $\begin{array}{c}\text { Loading } \\
\text { quantity(1.3times } \\
\text { safety factor) }\end{array}$ & $\begin{array}{l}\text { Maximum } \\
\text { stress(without } \\
\text { stiffener) }\end{array}$ & $\begin{array}{l}\text { Maximum } \\
\text { stress(with } \\
\text { stiffener) }\end{array}$ & $\begin{array}{c}\text { Maximum } \\
\text { displacement(without } \\
\text { stiffener) }\end{array}$ & $\begin{array}{l}\text { Maximum } \\
\text { displacement(with } \\
\text { stiffener) }\end{array}$ & \\
\hline \multirow{4}{*}{$\begin{array}{c}\text { Structural } \\
\text { analysis } \\
\text { of main } \\
\text { vessel }\end{array}$} & $\begin{array}{l}\text { DN1250 } \\
\text { gate valve } \\
\text { interface } \\
\text { DN1800 } \\
\text { gate valve } \\
\text { interface }\end{array}$ & $\begin{array}{l}\text { the weight } \\
\text { of DN } 1250 \\
\text { flange } \\
\text { interface } \\
\text { cryogenic } \\
\text { pump and }\end{array}$ & $\begin{array}{l}\text { Loading one } \\
\text { standard } \\
\text { atmospheric } \\
\text { pressure (the } \\
\text { atmospheric }\end{array}$ & 83.62 & 69.15 & \multirow{4}{*}{$4.28 \mathrm{~mm}$} & \multirow{4}{*}{$2.32 \mathrm{~mm}$} & 205 \\
\hline & $\begin{array}{l}\text { The sun } \\
\text { simulator }\end{array}$ & $\begin{array}{l}\text { its } \\
\text { accessory }\end{array}$ & $\begin{array}{l}\text { pressure of the } \\
\text { flange opening is }\end{array}$ & 112.58 & 106.23 & & & 205 \\
\hline & $\begin{array}{l}\text { Spectral } \\
\text { calibration } \\
\text { tank }\end{array}$ & $\begin{array}{l}\text { parts on the } \\
\text { vessel top is } \\
4.5 \mathrm{t} \text { and } \\
\text { one }\end{array}$ & $\begin{array}{l}\text { to the area), and } \\
\text { the DN1250 } \\
\text { flange interface }\end{array}$ & 85.26 & 79.36 & & & 205 \\
\hline & $\begin{array}{l}\text { The main } \\
\text { vessel } \\
\text { saddle }\end{array}$ & $\begin{array}{l}\text { standard } \\
\text { atmospheric } \\
\text { pressure is } \\
\text { loaded }\end{array}$ & $\begin{array}{l}\text { above the vessel } \\
\text { has the load of } \\
\text { 5.85t. }\end{array}$ & 89.23 & 70.26 & & & 235 \\
\hline
\end{tabular}

The figure 10 shows that under atmospheric pressure and the effect of gravity, the displacement produced by vacuum vessel and the stress received are significantly reduced, which meets the design requirements of GB150 vacuum vessel design manual.

\section{Conclusion}

This thesis builds up the three-dimensional sketch of vacuum vessel through solidworks. The limited model is also made by importing the ANSYS Workbench. After the analysis of the stress and displacement of the established model under atmospheric pressure and gravity and the transform of the model by reinforcement with steel, the following conclusion is conducted.

(1) Using the finite element analysis can quickly find the weak mechanism of mechanical structure, and provide theoretical basis for the improvement of structure in the future. The reinforcement to the vessel significantly increases the tolerable strength of the vessel. The maximum stress is from 197.95 Mpa to $151.51 \mathrm{Mpa}$, which greatly improves the stability of the vessel and saves the cost.

(2) The design process of the vacuum vessel requires repeated iterations, needing not only the experience manual, but also the finite element analysis tool, with which, the optimization design can be realized better, making it meet the design requirements while still with guarantee of saving the material.

\section{Acknowledgements}

Project name: the project of Sichuan department of science and technology " manufacturing technology and application of large-scale intelligent environmental simulation equipment" (2016GZ0159)

"High vacuum molecular pump intelligent manufacturing workshop" (2016062), a comprehensive standardization and new model application project of intelligent manufacturing in the ministry of industry and information

\section{References}

[1]. Han xiao, Qi Yan. The finite element analysis and application of structural design for large vacuum vessel [j]. Spacecraft Environmental Engineering, 2009, 26 (2) ,p. 151-153.

[2]. Yu Qianxu, Liu Min, Liu Botao, et al. The ultra- low temperature and cold screen structure for large space simulators: CN, CN 201867309 U [P]. 2011. 
[3]. Pan Chunxiang, Ren Xiuhua, Li Xiang. 2014 Chinese version of Solidworks Basic Course [M]. Posts and Telecom Press, 2014.

[4]. Wu Yueshen. Safety Technical Manual for Pressure Vessel [M]. Beijing: China Machine Press, 1999.

[5]. Gao Yaodong. Essential Thirty examples in applications of mechanical engineering of ANSYS Workbench [M]. Publishing House of Electronics Industry, 2013.

[6]. China Standards Press. Steel Pressure Vessels [M]. China standards press, 1998.

[7]. Huang Bencheng, Chen Jinming. Vacuum vessel design [J]. China Space Science and Technology, 2002, 22 (3),p. 6-12.

[8]. Jin Long, Li Yuqi. The Finite element analysis of tower crane based on ANSYS Workbench [J]. Journal of Guilin University of Tchnology, 2015, 35 (2), p.408-412. 